Heavenly freedom, derivative freedom, and the value of free choices

\title{
SIMON KITTLE
}

Department for Christian Philosophy, University of Innsbruck, Karl-Rahner Platz 1, Innsbruck A6020, Austria

simon@kittle.co.uk

Abstract: Sennett (1999) and Pawl \& Timpe (2009; 2013) attempt to show how we can praise heavenly agents for things they inevitably do in heaven by appealing to the notion of derivative freedom. Matheson (2017) has criticized this use of derivative freedom. In this essay I show why Matheson's argument is inconclusive but also how the basic point may be strengthened to undermine the use Sennett and Pawl \& Timpe make of derivative freedom. I then show why Matheson is mistaken to claim that the value of free choice depends on an agent retaining the ability to change their mind; in so doing I demonstrate that some choices which result in fixed outcomes - a feature of the choices leading to impeccability - can indeed be valuable even if they cannot be undone.

\section{Introduction}

Traditionally Christian theology understands heaven as a place where God and the redeemed will dwell together, where "death will be no more, mourning and crying and pain will be no more", and where there will be nothing accursed or guilty to be found for the redeemed will see God's face. ${ }^{1}$ Thoughts like these, together with philosophical reflection on the idea of heaven as a place of perfect bliss due to communion with God, lead naturally to the conclusion that redeemed humans will be unable to sin in heaven. The redeemed, in other words, will be impeccable. ${ }^{2}$

The idea that the redeemed in heaven will be impeccable, however, stands in at least prima facie tension with another idea that arguably belongs to the orthodox view of heaven, namely, that the redeemed will be free. These two ideas are in tension because on at least one plausible view, possessing free will requires being able to choose between good and evil. But if the redeemed are impeccable, they will be unable to choose evil, and so would seem to lack free will. As Kevin Timpe says, "if the redeemed are kept from sinning, their wills must be reined in, at least in some way. And if their wills are reined in, it doesn't seem right to say that they are free" (Timpe (2014), 84). This problem, which Timpe calls the Problem of Heavenly Freedom, is that of reconciling the following two statements:

i. the redeemed in heaven have free will

ii. the redeemed in heaven are impeccable

In this paper my focus will be on incompatibilist solutions to this problem. I will call the position I defend the choice-based account of heavenly freedom. On this view, free will is about control and control is a matter of having a choice about something. This account traces back to the decisions people make while on earth to explain their presence in heaven. It is also compatible with, though does not require, the idea that tracing back to certain character-forming

\footnotetext{
${ }^{1}$ Revelation 21:4, 22:3 (NSRV).

${ }^{2}$ See (Gaine (2003), 1-3) for details of a handful of dissenters.
} 
decisions explains the impeccability which the redeemed have once in heaven. However, unlike the account presented by James Sennett (1999), which has recently been extended by Timothy Pawl and Kevin Timpe (2009; 2013), it does not appeal to tracing to explain the possession of free will in heaven. In the next section I will sketch some background by introducing the accounts of Sennett and Pawl and Timpe. In the section after that, I will defend and develop a recent argument offered by Benjamin Matheson (2017) against the idea of derivative free will on which both Sennett and Pawl and Timpe rely.

On the account I defend, an agent has free will only if she has a choice about some matter. It's a commonplace that some choices are trivial (the light blue one or the dark blue one?) while others are momentous (shall we emigrate?). The challenge for the choice-based view is to show that the choices the redeemed might have in heaven are in some sense important: that they are "worth having". This challenge is complicated by the fact that it's not clear what kind of value is needed to make a choice "worth having". And while I do not seek to offer a complete answer to that question here, in the final section I will (a) make the idea of a valuable heavenly choice plausible, and (b) address one recent objection which threatens to undermine the value of many (if not most) kinds of choice that a choice-based account of heavenly freedom might appeal to. The objection, also presented by Matheson, is that the value of free will is extrinsic and depends on the power it gives agents to change their minds.

\section{Character formation, derivative free will and heavenly freedom}

Many incompatibilist philosophers have suggested that the impeccability of the redeemed can be explained, at least in part, by the redeemed having formed their characters during their earthly careers. The general idea is that while on earth, and perhaps also in purgatory, a person makes a series of choices which form her character in a virtuous manner. These choices are understood to be undetermined and as fulfilling whatever criteria belong to one's favourite account of free will. Eventually, so the thought goes, an agent will form her character to be so virtuous that she is no longer capable of sinning. This account has been given recent prominence by Sennett $(1999,77)$ but the thought is not new. Daniel Whedon, for example, wrote the following in 1864:

Let us now suppose a being, such as man truly is, of a mixed character in another respect. Suppose him automatic in his perceptions, emotions, and desires, yet free and alternative in his volitions; capable of choosing either of diverse ways in a right direction or in a wrong instead. ... Again, let us suppose that this last being is able, by his free volitions, to modify his automatic propensions; namely, his intellections, emotions, and desires, so as to make them better or worse than they naturally were. Either he neglects to restrain them from excess or wrong direction; or he directs, impels, develops, trains, and enlarges them for wrong; or he restrains and confines them to their proper degree and to a right direction. Even his automatic faculties would thence derive a sort of secondary responsible character; at least for much, if not for all their so formed character, he would be volitionally and morally responsible. It is thus that a man's sensibilities, intellections, emotions, and beliefs become secondarily and consequentially responsible (Whedon (1864), 387, emphasis in original).

Whedon goes on to suggest that by exercising our free will we might "train up" our attitudes, emotions and desires so that they become fixed either toward good or evil. In each case we 
have what he delightfully calls a "self-superinduced necessity" in our character from which either good or bad actions flow. Significantly, and as Whedon $(1864,387-388)$ goes on to say, this view doesn't just explain how the redeemed might be impeccable, it explains how the redeemed might bear some responsibility for being impeccable and, indeed, responsibility for the actions which flow from that impeccable character. It is because the agent herselfformed her character that she can be responsible for it and the actions which flow automatically from it.

This view can be developed in several ways. For example, it's implausible to think that many (if any) will have formed their character such that they are incapable of sinning by the time they die. At death, most will still be able to sin and therefore be unfit for heaven. Sennett $(1999,77)$ addresses this by speculating that at death God supplies "whatever is lacking in our character" to bring us to the required state of perfection; Pawl and Timpe $(2009,409 \mathrm{fn}$. 36), by contrast, address this by appealing to the doctrine of purgatory as somewhere we continue to develop our character until it's perfected. ${ }^{3}$

Note that nothing yet has been said about heavenly freedom. The framework above is an account of impeccability and the agent's responsibility for that impeccability. It assumes the possession of earthly freedom but says nothing about the existence or scope of the agent's heavenly freedom.

One account of heavenly freedom which may be combined with the framework above is the idea of derivative freedom. According to this view, if someone forms her character in such a way that she inevitably does good at some later time, then when the person later performs a good action, she is not (or not just) derivatively responsible for what she is doing, but derivatively free. Sennett (1999) proposes such a view. Sennett co-opts the term 'libertarian' to refer to individual actions which are (or are immediately preceded by) undetermined free choices and the term 'compatibilist' to refer to actions which are proximately determined by the agent's character but which are the result of a character trait that was formed through the exercise of 'libertarian' decisions (Sennett (1999), 71). Thus, the labels 'libertarian' and 'compatibilist', for Sennett, apply to individual free choices. This labelling, however, is confusing and unnecessary. To begin with, those who identify as compatibilists according to the standard definitions would reject Sennett's definition of a compatibilist choice because it has a historical condition which is incompatible with global determinism. Moreover, precisely because determinism is typically defined globally ${ }^{4}$, and compatibilism is standardly understood as the thesis that free will is compatible with determinism so defined, we couldn't even articulate the standard compatibilist/incompatibilist divide using Sennett's terminology. Finally, there is no need to label things this way. We can simply label the undetermined decisions an agent makes "directly free" and the actions an agent performs of necessity, due to the character she herself has formed, "derivatively free".

Using these terms, Sennett's view can then be stated as follows. A person makes a series of undetermined choices during her earthly career. Some of these choices will contribute to the forming of her character. These choices are directly free and so are connected to the kind of control associated with locutions such as 'up to us'. This process of character formation continues until death, whereupon God completes the process on behalf of the agent. Crucial to

\footnotetext{
${ }^{3}$ Hybrid views are also possible. Such complications don't affect what I will say below.

${ }^{4}$ See e.g. (Peter van Inwagen (1983), 1), (John Martin Fischer and Mark Ravizza (1998), 14), (Kadri Vihvelin (2013), 3).
} 
Sennett's view is the suggestion that through making a series of choices which were intended to develop a good character, the person has implicitly consented to God's completing the character-formation process (Sennett (1999), 77-78). Once in heaven, all of a person's actions will be determined by her perfected character. The move which both provides an account of heavenly freedom and simultaneously reconciles (i) and (ii) is to suggest that these actions are derivatively free. The distinctive part of Sennett's view, then, is that the agent "derivatively freely performs" those actions which flow automatically from her settled character. Sennett does not argue that these "derivatively freely performed" actions are "up to" the agent, nor that the agent has a choice about them. Rather, he reasons backwards: because the agent is responsible for them, we should count them as freely performed (Sennett (1999), 77). On this account, the agent's heavenly freedom extends to everything that she does in heaven.

Pawl and Timpe have proposed a similar solution to the Problem of Heavenly Freedom in two recent papers $(2009 ; 2013)$, and re-presented by Timpe in a recent book (Timpe (2014)). Like Sennett, Pawl and Timpe are clear that when an agent in heaven performs an action from necessity due to her own self-formed character, that agent is acting freely (Pawl and Timpe (2009), 408). In other words, they too endorse the notion of derivative freedom. Still, their account of heavenly freedom differs from Sennett's in one significant respect. On Sennett's view, all actions performed in heaven are determined by one's character. Pawl and Timpe think this claim is too strong and have suggested that the redeemed might make undetermined choices in heaven (Pawl and Timpe (2009), 407). The character of the redeemed person will preclude her sinning, which secures impeccability. But this is consistent with saying that the redeemed agent might face undetermined choices between multiple good options. They give the example of someone who can choose between singing in the heavenly choir or playing the harp. Because both the options are good, allowing an undetermined directly free choice here does not risk compromising impeccability.

On Pawl and Timpe's account, then, the redeemed in heaven possess two kinds of freedom. When a redeemed person acts out of necessity from her own self-formed character, she will be acting derivatively freely; when she makes an undetermined choice, she will be acting directly freely. Pawl and Timpe argue that at least some of the undetermined choices a person can make in heaven will be "morally relevant" and thus of special value (more on this below). They summarize this richer view of heavenly freedom as follows: "while the redeemed's character in heaven need not determine that they sing songs of joy, it would preclude that they drop-kick the apostles ... [their characters] might not determine whether they run, plow or play, [but they] would preclude that the redeemed rape, pillage and plunder" (Pawl and Timpe (2009), 408). Pawl and Timpe think, like Sennett, that everything done in heaven is done freely, but for a slightly different reason: the undetermined choices and actions which follow from them are directly free, everything else is derivatively free.

Despite this richer view of heavenly freedom, I contend that Pawl and Timpe's solution to the Problem of Heavenly Freedom is the same as Sennett's. There are two reasons for this. The first is that Pawl and Timpe themselves appear to see the directly free decisions as 'added extras' to the freedom of the redeemed. They say, for example, that were there no instances of direct free will in heaven, and were "all the decisions of the blessed in heaven ... determined by their characters and the reasons they see for acting in various ways, that by itself wouldn't render them unfree" (Pawl and Timpe (2009), 408, my emphasis). Likewise, Timpe endorses Jesse Couenhoven's statement that "supremely free persons [including the redeemed in heaven] ... 
may sometimes make undetermined choices but that is no necessary part of their freedom" (Couenhoven, as cited in Timpe (2014), 89). So Pawl and Timpe do not see direct freedom as essential to heavenly freedom, and thus it's hard to see how it could be essential to their reconciliation of (i) and (ii). The second reason, most evident in (Timpe (2014)), is an apparent inclination to think that a successful account of heavenly freedom should enable us to say, not just that the redeemed make some free decision or other in heaven, but that the redeemed freely refrain from sinning. Timpe writes the following:

The redeemed will be incapable of willing any $\sin . .$. because of ... the character that the redeemed have formed in their pre-heavenly existence. Given the perfection of their character, they will see no reason to engage in sinful and wicked actions. But ... not being able to do some action because one doesn't see any reason for performing it doesn't mean that one lacks free will with respect to that action (Timpe (2014), 89, my emphasis).

In other words, Timpe wants 5 to reconcile not just (i) and (ii), but also (i*) and (ii):

$i^{*}$. the redeemed in heaven have free will with respect to refraining from sinning

Pawl and Timpe achieve this but only by appealing to the notion of derivative freedom. Their inclusion of some directly free choices into their account of heavenly freedom plays no role in reconciling $\left(i^{*}\right)$ and (ii). Thus, if the primary Problem of Heavenly Freedom is reconciling $\left(i^{*}\right)$ with (ii), Pawl and Timpe's solution is identical to Sennett's solution and relies entirely on the notion of derivative freedom. In the following section I will argue that this is problematic because the notion of derivative free will is suspect.

\section{Against derivative free will}

Benjamin Matheson has recently argued that tracing based accounts of heavenly freedom, including Pawl and Timpe's, are "untenable" (Matheson (2017), 4). He provides two reasons. The first is that the idea of derivative freedom is suspect. The second is that the value of free will is bound up with being able to change one's mind, but that once one's character is formed, certain kinds of change of mind are impossible, meaning that the value of one's freedom is severely limited. I agree with Matheson that the notion of derivative freedom should be rejected; this section develops the case against derivative freedom. However, I disagree with Matheson about the value of free will and in the following section I will show that the value of free will does not depend on being able to change one's mind.

Derivative freedom is the idea that an agent might perform an action at $t_{1}$ which makes it inevitable that she performs a further action at $\mathrm{t}_{2}$, and that despite being inevitable, the action performed at $t_{2}$ could properly be said to be performed freely. It is similar to the idea of derivative responsibility, but with the affirmation that the agent who inevitably acts in line with her character is acting freely. Many theories of free will, libertarian and compatibilist, make use of the notion of derivative responsibility. The paradigm case of derivative responsibility is the drunk driver. Suppose Sally drives drunk and injures a small child. Sally, who we suppose is a normal adult, knows that drinking drastically reduces one's ability to drive a car safely and knows that it is very dangerous to drink and drive. At the time at which Sally injures the child

\footnotetext{
${ }^{5}$ Timpe confirmed this interpretation in a Q\&A session at the University of York, October the 5th, 2017.
} 
we may agree that she could not have done otherwise. Being drunk, she was not in full control of her vehicle. Nevertheless, we still hold her responsible because she could foresee the possible consequences of driving drunk and yet still choose to get drunk without (say) giving her keys to a friend or booking a taxi home.

The idea of derivative responsibility is straightforward and not especially controversial. Derivative freedom, on the other hand, is a very different matter. When Sally is behind the wheel running over the small child, is she doing that freely? Arguably, according to Sennett and Pawl and Timpe, the answer would seem to be yes because Sally's drunken behaviour can be traced back to an earlier decision. But Matheson suggests that "it's not clear it makes sense to say that Sally acts freely in hitting the child" as "the whole point of appealing to tracing here is because Sally seems morally responsible even though she lacks control over her actions, and if she lacks control she lacks free will" (Matheson (2017), 5). In other words, we employ the notion of derivative responsibility precisely because the agent is not exerting the kind of control (i.e. freedom) required to be morally responsible.

As far as drink-driving style cases go, I think this assessment is dead right. And if such cases are representative, this point would count against Sennett's methodology (cited earlier) where we reason as follows: the agent is responsible, therefore the agent is acting (derivatively) freely. Drink-driving style cases caution against such reasoning and cast some doubt on the notion of derivative freedom, and to the degree that they do so, they will undermine Sennett's account and the reconciliation of ( $i^{*}$ ) and (ii) that Pawl and Timpe are keen to secure.

Perhaps, however, drink-driving style cases are not representative. In particular, they might not be analogous to the case of the redeemed who have formed their character such that they can no longer sin. Here is one way of developing this idea on behalf of the proponent of derivative freedom.

Such a person might concede that Sally (the drunk driver) is indeed out of control and so lacks freedom. But, it might be suggested, this is not due solely to Sally "not having a choice" about what she's doing while drunk. The proponent of derivative freedom might suggest that there is a second kind of control which Sally also lacks: the kind of control which comes from successfully exercising one's capacities and abilities to implement some goal. Let's call the kind of control possessed when an agent can make an undetermined decision choice-based control. This is the control an agent has when she "has a choice" about something, when something is "up to her". It is the control associated with direct freedom. And let's call the second kind of control - the kind which derives from the successful exercise of one's capacities to act implementation control. I call it implementation control because it is the control possessed when an agent can act so as bring about an already settled-upon goal. For example, suppose that Suzy has formed her character to be very virtuous and automatically comes to the aid of anyone whom she sees needs help. When Suzy sees an old man fall over she rushes over and tends to him, and she does this "without thinking" - without choosing to do it. One of her standing goals is "to come to the aid of those in need" and when she encounters such a situation she pursues that goal: this involves her exercising various capacities and abilities as the situation dictates in order to implement that already settled-upon goal. Once she's formed her character in such a way, it's not up to Suzy whether she comes to the old man's aid, but her succeeding in that endeavour requires accurate control over what she does. 
With this distinction in hand, the proponent of derivative freedom might reply to Matheson as follows: I agree that Sally lacks control, and that in order to explain her responsibility we must trace back to a previous occasion where Sally exercised the relevant control. But Sally actually lacks two kinds of control, and that - her lacking both forms of control - is why we must trace back. The redeemed in heaven do lack choice-based control but they do not lack implementation control. Moreover, the implementation control that they exercise is exercised to realize a goal that was itself settled by earlier exercises of the agent's choice-based control (during their earthly career). And that is why we can call their actions free.

This envisaged response is one interpretation of Sennett's claim that derivative freedom entails direct freedom (Sennett (1999), 75). It's the idea that an exercise of implementation control only counts as an exercise of freedom if what is being implemented was itself the result of an exercise of choice-based control. This is, I think, the best way to develop the idea of derivative freedom and such a development is immune from Matheson's criticism. Even so, I will now argue that the notion of derivative freedom is superfluous and is an ad hoc addition used by Sennett and Pawl and Timpe solely in order to be able to affirm that the redeemed freely refrain from sinning.

I begin by accepting that we can indeed identify two notions of control: choice-based control and implementation control. In the account of derivative freedom just sketched, instances of implementation control count as instances of freedom when they arise from a behavioural disposition the possession of which can be traced back to an instance of choice-based control. The challenge for such an account is to justify this step: why call such exercises of (implementation) control instances of freedom? Why not simply say that freedom is possessed at the point of choice, and the agent is merely derivatively responsible at later times? Here is one way of seeing the importance of these questions. Suppose we were to survey the relevant philosophical and scientific literature on control. We might identify, say, ten different forms of control. Once we had such a list, those of us interested in free will might then ask which forms of control are relevant to free will (and why). Simply being a kind of control doesn't guarantee relevance: a heating system might be controlled by a thermostat control system, but that control system doesn't have free will. So for any given notion of control, we need to ask whether it is relevant to free will.

It is, I think, very intuitive that choice-based control is relevant to free will. Choice, as Thomas Scanlon writes, "has obvious and immediate moral significance" (Scanlon (1988), 151). It is at the core of our conception of ourselves as human beings and "absolutely central to many of our social institutions, from criminal responsibility to the markets, from democracies to marriage" (Vierkant, Kiverstein and Clark (2013), 1). And of course, we tend to excuse people from moral responsibility when they could not have done otherwise - that is, when they had no choice.

But what about implementation control? Is that relevant to free will? Should some of those actions which are instances of implementation control be labelled 'free'? There are two points which I think count against this idea.

First, there are cases of derivative responsibility for which where is no corresponding act which could be labelled '(derivatively) free'. Consider the following amendment to the drunk driver case above: Sally gets into her car, drives off and promptly falls asleep due to being so drunk. The car trundles on for 30 seconds before running over a small child. In this case, when she 
runs over a child, Sally is asleep and therefore not exerting any control. But she is derivatively responsible for running over the small child.

What this shows is that proponents of the idea of derivative freedom will still need to endorse an independent account of derivative responsibility - i.e. an account of derivative responsibility that does not rely on finding an action corresponding to that which the agent is responsible for, an action it can label 'free'. Proponents of derivative freedom need such an account to explain the modified drunk driver cases, like the one immediately above, because there is no action in such cases: Sally is asleep, and so not acting, and so a fortiori not "derivatively freely acting". Yet she is derivatively responsible. So there are cases where the agent is derivatively responsible for $X$, despite not exercising any implementation control with respect to $X$. And the proponent of derivative freedom will need a theory of derivative responsibility to cover such cases. But and this is the key point - such a theory will also be able to explain the agent's derivative responsibility in cases where there is implementation control. So the notion of derivative freedom is simply not needed to explain derivative responsibility.

This shows that the following reasoning Sennett proposes is flawed. Sennett writes that "while it is true that the agent [who acts out of necessity from her character] could not have done otherwise in the relevant sense, it is also true that the agent can nonetheless be held morally responsible" and that this attribution of responsibility licenses the attribution of freedom (Sennett (1999), 77). But we can now see such a move is mistaken. And so we ask once more: if the theory of derivative responsibility to which the proponent of derivative freedom is already committed fully explains the agent's derivative responsibility in cases where there is implementation control, and does so without appealing to any notion of derivative freedom, what is the justification for introducing the notion of derivative freedom? So far we have no answer.

The second point highlights that there is nothing in and of the notion of implementation control itself which should lead us to think it is a form of control which would suffice for free will. We could make this point by pointing to man-made control systems such as thermostat-controlled heating systems: they have a goal written into them, and they bring about that goal via implementation control, but they are not morally responsible for doing so. Or we might cite cases of non-human animal agency where a creature has some goal and exercises implementation control to bring about that goal, while making no choice with respect to that goal, and perhaps not even having the capacities that would have allowed that goal to be assessed or critiqued. But these examples might be dismissed by suggesting there are other differences which make them non-analogous. Thus, the strongest way of making this point is to point to cases where humans exercise implementation control in the absence of choice-based control and where there is no temptation to consider them responsible. I think the following is such a case:

Suppose that Robyn has a fear of rabbits, and if she sees one, she runs in the opposite direction. Robyn did nothing to cultivate this fear; it was the result of environmental factors entirely beyond her control. Indeed, Robyn has repeatedly tried to rid herself of her phobia, though she has been unsuccessful. When she sees a rabbit, then, she flees. Interestingly, the implementation control she exercises over her running away is flawlessly executed: she executes a perfectly controlled 180 degree on-the-spot turn, assesses the terrain accurately, and accelerates to her maximum sprinting speed within seconds. 
I do not think there will be much temptation to consider Robyn morally responsible for her fleeing, especially given the dialectical context, which is a debate among incompatibilists. ${ }^{6}$ Clearly, incompatibilists who emphasize the need for choice are not going to judge Robyn responsible for her behaviour here. But neither, I think, will so-called source incompatibilists. Source incompatibilists hold that what's important for moral responsibility is that the agent's behaviour issue ultimately - i.e. indeterministically - from the agent's will and intellect.7 But Robyn's disposition to flee derives from environmental factors beyond her control, and her behaviour flows inevitably from that disposition. Moreover, Robyn has done everything she can to rid herself of her phobia and so it can't be suggested, say, that she has implicitly consented to, or in any way endorses, her phobia.

If it is correct to say that Robyn is not responsible, then this case involves a perfect instance of implementation control without any derivative responsibility. And what this suggests assuming this judgement about Robyn's non-responsibility is correct - is that implementation control in and of itself is not sufficient for free will. That is, implementation control is not a form of control that by itself allows us to hold agents morally responsible for their behaviour. And that means we should not be led to describe an action as 'derivatively free' simply in virtue of the presence of an exercise of implementation control.

So we don't need the idea of derivative freedom to explain derivative responsibility. And the second kind of control appealed to in this envisaged account of derivative freedom does not in and of itself warrant the name 'freedom'. Why then introduce the notion? The only answer, it seems, is to be able to affirm a certain theological proposition, namely, that the redeemed in heaven are not merely derivatively responsible for their impeccability but they freely refrain from sinning while in heaven. My contention is that introducing an otherwise unneeded notion solely for that purpose is ad hoc and is in the end no real reconciliation of (i*) and (ii) but merely a reconciliation by stipulative definition.

Moreover, there is at least one positive reason to be reluctant to use the term 'free' in the way proposed by proponents of derivative freedom. This reason stems from the observation that the notion of control is time-sensitive in a way that the notion of responsibility is not. Consider a standard case of someone making a choice and being responsible for it. Suppose that David lied to a friend on November the 1 1 st, 2010. It was a standard choice and David was in full control. Now, some eight years later, David is responsible for having lied: that is, he is still responsible, now, for having lied. But David isn't controlling that lie now. David exerted control over what he decided back when he decided. He made his decision to lie, now he must live with it. And living with it includes being responsible for it: being responsible for it now. Why is this important? Well, the proponent of derivative freedom wants to call some but not all instances of implementation control 'free'. Those instances of implementation control deemed special are those which stem from character traits or dispositions that were themselves formed by choicebased control. The dependence on a prior exercise of choice-based control is the essential characteristic of the accounts of Sennett and Pawl and Timpe that we're considering here. But

\footnotetext{
${ }^{6}$ I would like to thank an anonymous referee for emphasising the need to clarify the audience and to address the following point.

7 They are best thought of as 'non-choice theorists' because those who argue that choice is needed for freedom will often agree that free will requires the agent to be the source of their behaviour, it is just that choice-theorists will contend that the agent only becomes the source in the relevant sense by choosing: desires and intentions which indeterministically arise in one's mind do not bestow control.
} 
that choice-based control was exercised in the past. The agent is no longer making the decision which has made the all-important difference, no longer exerting the relevant kind of control. But if that's so, then we should seek to endorse a theory which attributes present-day responsibility but should shy away from affirming that the agent is now exercising the relevant kind of control. To put the point a little differently: the control which makes the crucial difference isn't implementation control, but choice-based control, which in the cases under consideration was exercised in the past and is no longer possessed. But freedom just is the control required for moral responsibility - Timpe, at least, explicitly endorses this definition of 'free will'. To label certain exercises of implementation control 'free' is to contravene this definition and introduce a new technical usage of 'free' simply in order to be able to utter a certain theological statement.

I accept that the above points do not constitute a knock-down case against the notion of derivative freedom, and I accept too that part of my case relies on agreeing with the judgement that Robyn is not responsible. Nevertheless, I think the onus is now on proponents of the derivative freedom to (a) provide a detailed account of what it is meant to be, how it relates to notions of control, and interacts with the wider theory of derivative responsibility, and (b) justify its introduction, ideally on independent grounds and not solely in order to facilitate the affirmation of a theological proposition by stipulative definition.

\section{Heavenly freedom and the value of choices}

I've argued that the concept of derivative free will should be rejected. Free will is about choicebased control, not implementation control. With derivative freedom off the table, an agent's heavenly freedom will be limited to those things that the agent has a choice about. In the remainder of the paper I will defend the choice-based account of heavenly freedom from a challenge recently pressed by Matheson in the paper already cited above.

I begin by sketching the view to be defended. I call this view the choice-based view of heavenly freedom because it explicitly identifies free will with having a choice. It is best to think of it as a family of views, though, as there are a number of ways it can be worked out. Indeed, choicebased views can share many features of the accounts presented by Sennett and Pawl and Timpe. The idea that a person might make choices while on earth which help to form her character and that once her character is perfected it will no longer possible for her to sin, is very amenable to the choice-theorist. But the choice-theorist will not say that the redeemed freely avoid sinning in heaven (which, after all, they do not control), only that the redeemed are derivatively responsible for not sinning. The main challenge for the choice-theorist is to give some idea of how the types and number of choices that an agent might face in heaven add up to a level of freedom that it would be desirable to have.

Some useful suggestions were made on this topic by W. S. Anglin (1991). We begin with the observation that having a perfected character in the sense required for presence in heaven need not mean having all of one's abilities perfected. Instead, it means being perfected morally. Given this, Anglin speculates that it might be possible, for example, to forget things in heaven. If it is possible to forget things in heaven, then some actions which one would only perform once, were one to remember having performed them, would become performable over and over. What use is this? Anglin gives the example of someone who enjoys maths spending some time proving a certain mathematical theorem. He then asks us to imagine that person forgetting the 
proof. The person might go through the steps of proving the theorem a second time and this need not be fruitless or pointless, Anglin suggests, because (a) studying mathematics can be an intrinsically enjoyable experience and, more importantly, (b) could be seen as putting the person in touch with "a kind of transcendent beauty" (potentially some aspect of God) (Anglin (1991), Ch 7, sect 7). It would follow that decisions about whether to perform such activities would be valuable. Anglin's idea could be extended by proposing that those in heaven might be able to choose to forget certain things precisely in order to be facilitate experiencing certain things anew, or perhaps, to choose to experience things in a way that would not result in a complete memory of them in the first place. ${ }^{8}$

Richard Swinburne has also advocated the idea that the freedom of those in heaven will involve making choices. He has pointed out that in heaven there will be no obstacles to performing the actions and having the experiences which are of supreme worth (Swinburne (1989), 189). Moreover, while its true that the saints will be unable to sin, the saints will have increased knowledge and new capacities that will enlarge the range of things they could choose to do. Swinburne maintains that the most important activity of the redeemed will be cooperative worship (Swinburne (1989), 189). In this, the redeemed will have some measure of free will. They won't retain a choice about whether to worship, but they might well have a choice about how to worship. For example, perhaps Anglin's mathematician could choose to worship God by proving a mathematical theorem, or by helping others to see the beauty of some mathematical theorem (thus showing them an aspect of God's beauty), or by doing something else entirely.

Pawl and Timpe's work on this topic is useful too. I have argued against Pawl and Timpe's use of the notion of derivative freedom. But that does not mean their comments concerning the kinds of undetermined choices that those in heaven might face are off target. They give one or two concrete examples, one of which I've already mentioned: the choice between whether to sing or play the harp in worship, which echoes Swinburne's thoughts. Timpe also argues that some of the choices the redeemed might face could be "morally relevant" in that while all the options for any given choice will be good, some of the options might be better than others, resulting in the existence of some supererogatory actions in heaven (Timpe (2014), 93). Such decisions would be morally weighty in two ways: first, a person could be judged better for having performed a supererogatory action, even though leaving it undone would not be wrong; second, someone might improve her character by performing supererogatory actions. These latter points are controversial and Steven Cowan $(2011,430)$ has raised some important objections to them. By contrast, Christopher Brown (2015), while agreeing with some of Cowan's points, has argued that the redeemed will face "morally grave" choices in heaven: a kind of moral choice which doesn't depend on the existence of supererogatory actions. But whether or not it is plausible to think that the redeemed will face any moral choices - and it is certainly not obvious that they won't - the above sketch, highlighting the complementary ideas of Anglin, Swinburne and Pawl and Timpe, makes it very plausible to think the redeemed could face a wide range of choices in heaven, many of which would be valuable and significant (even if not morally so).

Against that background, I want to consider Matheson's suggestion that "the reason why significant freedom is valuable is that it allows persons to make up their own minds" but that this value is undermined unless the person also retains the freedom to "change their minds at later

${ }^{8}$ These ideas came out of a conversation with David Worsley. 
times" (Matheson (2017), 7-8, emphasis in original). Now, Matheson's charge is issued in the context of a discussion of the problem of evil and his focus is on what Alvin Plantinga called significant freedom - namely, the freedom to choose between morally good and bad options. However, his point would seem to apply, if it applies at all, more widely. Not only is one of the two examples Matheson uses to make his point non-moral in character (and thus not an instance of significant freedom in Plantinga's sense), Matheson himself says that his argument promises to teach us "some important lessons" about the nature of free will in general (Matheson (2017), 4). Matheson's objection thus threatens the kind of account I endorse in two ways. First, and as already mentioned, the idea that the agent's forming her own character plays at least some role in her being impeccable in heaven is a natural fit for the choice-theorist. But to the degree that character-forming choices are successful - i.e. result in a fixed character Matheson's point (if correct) would render them worthless. Second, Matheson's point also threatens the value of any "one off" choices the redeemed face in heaven, choices concerning things which the agent would then be unable to change her mind about. On the choice-based account of heavenly freedom, this would reduce the scope of valuable heavenly freedom, thus weakening the account. To support his claims Matheson asks us to consider two examples involving political freedom. The first is that of slave contracts:

A slave contract is one which when a person enters into it, she thereby gives up her rights. The person, in effect, lets herself become the property of some other person; she who enters into a slave contract agrees to become another person's slave. But a person does not have the political freedom to enter into a slave contract. No one is free to enslave a person, not even the person herself (Matheson (2017), 8).

Matheson comments that "one reason slave contracts seem bad is because they stop a person being able to change their mind" (Matheson (2017), 8). The second example is democracy:

...what is valuable about democracy is that it allows the people to choose who is going to govern them. That is, it gives people the political freedom to make up their own minds about who going to govern them. It is not, however, possible on a democratic model of government for the people to decide at a particular time to always be governed be a particular leader or political party. In countries where this happens - that is, countries that are officially democratic, but which are not in reality democratic-it seems that the people lack the sort of freedom that people in properly democratic countries have (Matheson (2017), 8).

Matheson then says: "one reason that democracy seems valuable is because it ensures that people can later change their minds" (Matheson (2017), 8). And he goes on to conclude that "the value of making up one's mind is, in fact, dependent on one being able to change one's mind at a later time" (Matheson (2017), 8). By way of support, he asks us to consider a case where we have the opportunity to vote for a candidate, but voting for that candidate would result in us losing the freedom to vote at the next election - i.e. it would result in losing the ability to change our minds politically. This would, he says, "undermine the prima facie value our freedom to vote for the candidate" initially had (Matheson (2017), 8).

These examples are useful to think about, but Matheson's conclusions are much too quick. There are, for instance, plenty of reasons why slave contracts are bad, reasons which have nothing to do with losing the ability to change one's mind. Suppose that a slave contract lasts 
only one year, after which the person becomes free again. After a year the person would have to decide to enslave himself again. Each year would present an opportunity to change one's mind. But that doesn't appear to remove much if any of the badness of such a slave contract. And if such a contract is less bad, it could just be a result of the reduction in the length of the contract, as opposed to the reintroduction of the ability to change one's mind. In other words, Matheson has not shown that it is losing the ability to change one's mind that constitutes the badness of entering into a slave contract. Furthermore, even if losing the ability to change one's mind does play that role in this example, that hardly establishes the general point that losing the ability to change one's mind is always undermines a choice's value.

The democracy case doesn't show what Matheson wants either. To begin with, it's not clear that being able to vote in a subsequent election several years down the line amounts to being able to change one's mind. If you voted Labour in the 2005 UK general election and then voted differently in the 2010 general election, there is a good case for saying, not that you changed your mind, but simply that you made up your mind differently the next time around. Typically, changing one's mind refers to a situation where you decide at $t_{1}$ to $A$ at $t_{3}$, but then at sometime $t_{2}$ before $t_{3}$, you decide to $B$ at $t_{3}$ instead. Even putting that complication to one side, however, Matheson's point is not established. Indeed, Matheson makes a very strong claim: the value of free will "depends on" being able to change one's mind, and if one loses the ability to change one's mind, then the value of one's previous choice is "undermined" (Matheson (2017), 8). That is wildly implausible.

Imagine bumping into Luke Skywalker at the after-party of the Death Star Destruction Celebrations and trying to convince him that his free decision to blow up the Death Star really wasn't that valuable because he's now unable to change his mind about it. Or, again, complaining to Éowyn after she'd slain the Witch-king of Angmar: "you know, what you did was all very well, but it would've been better if you had simply restrained the Lord of the Nazgûl somehow, because then you would have been able to change your mind and let him go and it's clear, isn't it, that so deciding would have been more valuable?" You won't, I think, meet with much success. We might note, too, that far from undermining the value of one's choice, being able to change one's mind in these cases would seem to be a bad thing (I will say a bit more about this below).

Matheson's strong claim - that the apparent value of free will is undermined - is implausible even in Matheson's chosen realm of the political. Consider two groups of people. One has no say over who governs them. The other can vote to elect a government which will then be installed for life. Once the second group has voted, they'll be unable to change their minds. It's true, of course, that a system of regular elections is preferable to the situation of those in the second group, but those in the second group have it better than those in the first. Their choice has some value. Therefore, Matheson is simply mistaken when he writes "the value of politically making up one's mind is dependent on being able to politically change one's mind later on" (Matheson (2017), 8).

Is there a weaker claim in the vicinity that might still cause trouble for a choice-based theory of heavenly freedom? Perhaps something like this: having the power to make up one's mind about $X$, and then to change one's mind about $X$ at a later time, will, all other things being equal, be more valuable than simply having the power to make up one's mind about $X$. The claim here isn't that there is no value in solely being able to make up one's mind, only that there is more 
value in being able to make up one's mind and also to change it. If this were right, the choices through which someone formed her character to be virtuous would have more value if the person were able to choose to undo her virtuous character than if her character became forever fixed. This would be problematic (although not fatal) for accounts of heavenly freedom which appeal to character formation to explain impeccability: it would be harder for proponents of these accounts to argue that the freedom the person exercised on the way to heaven was valuable. There are two problems for Matheson here. First, this weaker claim wouldn't lead to the conclusion he wants. Matheson's argument, as it applies to the choice-based theory of heavenly freedom, is as follows: (1) free will without the ability to change one's mind has no value; (2) therefore, if we are to affirm that free will has value we must posit the ability to change one's mind too; (3) the redeemed in heaven will be able to change their minds only if they are able to undo their perfected character, which amounts to choosing to move away from God and so is a case of sinning; (4) the freedom of the redeemed should be valuable; (5) therefore, the freedom of the redeemed must include their being able to sin. This conclusion would preclude a reconciliation of (i) and (ii). But given only the weaker claim, premise (1) is left entirely unsupported and so the argument doesn't get going.

Matheson's second problem is that the weaker claim is false too. There are cases where having the ability to change one's mind is not desirable and would not add value to one's freedom. Suppose there is a swarm of wasps in your office. And let's suppose if you open the window they'll fly out but buzz around waiting for the window the re-open. You have one, and only one, opportunity to let them out. So you have a choice, but won't be able to change your mind. You decide to let them out. Is the choice you have here less valuable because you won't be able to choose to let the wasps back in? I don't think so. Arguably the same is true of the Skywalker and Éowyn examples: giving them the ability to change their mind would not make the choices they made more valuable. No, the straightforward conclusion is that sometimes having the ability to change one's mind would not make a choice more valuable.

We can, however, go further. There are cases where lacking the ability to change one's mind at a later point seems to increase the value and significance of some choice. Consider the person who faces a decision about whether to donate a kidney to a relative. Such a decision would be considered by many to be supererogatory but clearly, in normal cases of such a choice, it is not possible to change one's mind. Equally clearly, though, such a choice is valuable and significant. Moreover, a good case could be made for saying that the decision to donate a kidney carries a special kind of value - potentially moral value - precisely because it cannot be undone. This suggests that not only does lacking the ability to change one's mind not always reduce the value of a choice, sometimes it increases the value of a choice. Indeed, suppose someone choose to donate a kidney, but only on the condition that she could change her mind and demand it back at any time. That person's decision is clearly less valuable precisely because she has demanded a possible future reversal.

And again, this point also applies to the Skywalker and Éowyn examples: if they had the ability to change their minds, the value of their choices would be reduced. Part of the reason for this, we might suspect, is that being able to change one's mind in these cases does nothing except keep open the possibility of some bad state of affairs coming to pass. A similar thought goes some way to explaining why regular elections are valuable. Many of the reasons why facing a single election to install a government for life would be less valuable than regular elections is because of the risk of potential bad consequences: the rulers might allow the system to reflect 
their biases and evils; the power might corrupt them, leading to tyranny; the elected government might prove to be inept at handling some unforeseen crisis or danger (even if they had governed excellently in the conditions under which they were elected). Having regular elections holds out the hope of preventing or mitigating these kinds of negative consequence.

In each of these cases then, being able to change one's mind is valuable because it serves to prevent, mitigate or undo some potential future harm - moral or otherwise. Interestingly, though, these risks are not going to exist in heaven and so these reasons for valuing the ability to change one's mind will not exist in heaven either. To be clear: I am not suggesting the only reason being able to change one's mind is valuable is because it facilitates avoiding or mitigating some evil. Instead, I'm pointing out that this seems to be what unifies the selection of examples I've presented. Moreover, we have at least some reason to think the examples couldn't be modified in order to avoid the present point, because heaven will exclude the possibility of such threats and harms. Obviously, there is much more that can and should be said about the value of choices (both generally and those that might be had in heaven), but enough has been said to dispatch Matheson's argument against the choice-based theory of heavenly freedom.

\section{Conclusion}

In this paper I have developed and defended an argument against the notion of derivative free will. This poses a challenge for Sennett and Pawl and Timpe whose solutions to the Problem of Heavenly Freedom rely on that concept. In addition, I have challenged Matheson's claim that the value of free will depends on being able to change one's mind. There is no reason to doubt that the free choices by which one secures the fittingness of one's character for heaven have value. Moreover, the examples surveyed towards the end of the paper provide every reason to think choices which result in fixed outcomes - i.e. choices where we won't be able to change our minds - can often have enormous value. ${ }^{9}$

\footnotetext{
${ }^{9}$ This work was funded by the Sir John Templeton Foundation, Grant No. \#57397, whose support I gratefully acknowledge.
} 


\section{References}

ANGLIN, W. S. (1991) Free Will and the Christian Faith: Clarendon Press.

BROWN, C. M. (2015) 'Making the Best Even Better', Faith and Philosophy, 32(1), 63-80.

COWAN, S. B. (2011) 'Compatibilism and the Sinlessness of the Redeemed in Heaven', Faith and Philosophy, 28(4), 416-431.

FISCHER, J. M. and RAVIZZA, M. (1998) Responsibility and Control: A Theory of Moral Responsibility. Cambridge: Cambridge University Press.

GAINE, S. (2003) Will there be free will in heaven? Freedom, impeccability, and beatitude. London: T \& T Clark.

MATHESON, B. (2017) 'Tracing and heavenly freedom', International Journal for Philosophy of Religion, 20(4), 1-13.

PAWL, T. and TIMPE, K. (2009) 'Incompatibilism, Sin, and Free Will in Heaven', Faith and Philosophy, 26(4), 398-419.

PAWL, T. and TIMPE, K. (2013) 'Heavenly Freedom', Faith and Philosophy, 30(2), 188-197.

SCANLON, T. M. (1988) 'The Significance of Choice', in McMurrin, S. M. (ed.) The Tanner Lectures on Human Values: Volume 8. Cambridge: Cambridge University Press, 149-216.

SENNETT, J. F. (1999) 'Is There Freedom In Heaven?' Faith and Philosophy, 16(1), 69-82.

SWINBURNE, R. (1989) Responsibility and Atonement. USA: Oxford University Press.

TIMPE, K. (2014) Free will in philosophical theology. (Bloomsbury studies in philosophy of religion). New York, NY: Continuum.

VAN INWAGEN, P. (1983) An essay on free will. Oxford: Clarendon Press.

VIERKANT, T., KIVERSTEIN, J. and CLARK, A. (2013) 'Decomposing the Will: Meeting the Zombie Challenge', in VIERKANT, T., KIVERSTEIN, J. and CLARK, A. (eds.) Decomposing the Will: Oxford University Press, USA, 1-30.

VIHVELIN, K. (2013) Causes, laws, and free will: Why determinism doesn't matter. New York: Oxford University Press.

WHEDON, D. D. (1864) The Freedom of the Will. New York: Carlton \& Lanahan. 